\title{
Profiling Energy Consumption in a Residential Campus
}

\author{
Ankur Sial $^{1}$, Abhishek Jain $^{1}$, Amarjeet Singh ${ }^{1}$, and Aniket Mahanti ${ }^{2}$ \\ ${ }^{1}$ Indraprastha Institute of Information Technology (IIIT-Delhi), India \\ \{ankur11024, abhishek11005, amarjeet\}@iiitd.ac.in \\ ${ }^{2}$ University of Auckland, New Zealand \\ a.mahanti@auckland.ac.nz
}

\begin{abstract}
We present preliminary analysis of energy consumption in a residential academic campus in India. We deployed over 200 smart electric meters across the campus, collecting over 5 million data points every day. The analysis is based on data collected over a period of five months. Our results show skews in energy consumption for different electrical loads on campus. For example, a large proportion of the energy consumed in the campus is due to fixed electrical appliance infrastructure such as HVAC and UPS. We classify and group the locations based on their energy consumption profile during the day and week. Our work is a first step towards understanding energy consumption of an academic community. The results can be useful in implementing energy conservation strategies in the campus.
\end{abstract}

\section{Categories and Subject Descriptors}

C.4 [Performance of Systems]: Measurement techniques

\section{Keywords}

Smart meters; deployment; energy consumption; sMAP

\section{INTRODUCTION}

Climate change is a major concern for the world's population. Over $65 \%$ of India's electricity is generated from thermal power plants fueled by non-renewable resources like coal. ${ }^{1}$ While finding green energy sources is necessary, it is pertinent that we reduce our global energy footprint. A first step towards this goal is being informed of our energy consumption habits. Smart meter deployment is underway in India along with upgrading the power grid to a smart grid.

There has been limited work in characterizing energy consumption of consumers in the developing world. Prior work

\footnotetext{
${ }^{1}$ http://www.powermin.nic.in/indian_electricity_ scenario/introduction.htm
}

Permission to make digital or hard copies of all or part of this work for personal or classroom use is granted without fee provided that copies are not made or distributed for profit or commercial advantage and that copies bear this notice and the full citation on the first page. Copyrights for components of this work owned by others than the author(s) must be honored. Abstracting with credit is permitted. To copy otherwise, or republish, to post on servers or to redistribute to lists, requires prior specific permission and/or a fee. Request permissions from permissions@ acm.org. CoNEXT Student Workshop'14, December 2, 2014, Sydney, Australia.

Copyright is held by the owner/author(s). Publication rights licensed to ACM. ACM 978-1-4503-3282-8/14/12 ...\$15.00.

http://dx.doi.org/10.1145/2680821.2680827.

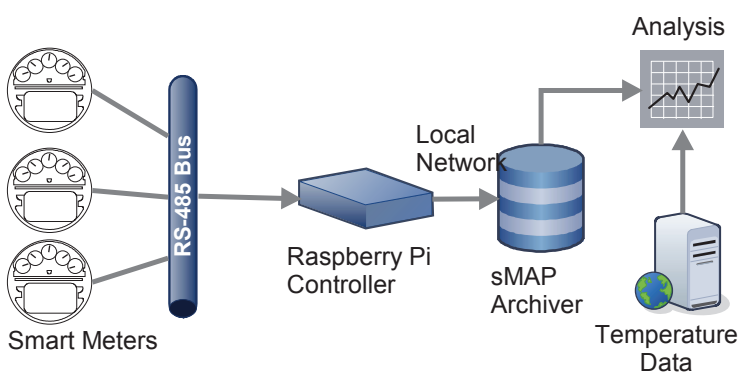

Figure 1: Data collection architecture

has focused on understanding energy consumption in developed economies [1], benchmarking energy efficiency of buildings [2], and energy consumption prediction [3], among other things. In this paper, we present an energy consumption profile of an academic residential campus in India. To the best of our knowledge, this is the first work to characterize energy consumption of a campus using smart meter data in an emerging economy.

Our work complements prior work by characterizing energy consumption of a residential campus consisting of over 900 students and faculty. The campus electricity utility has implemented a time of day tariff scheme. The utility applies a $20 \%$ surcharge during peak hours (between 3 p.m. and 11 p.m.), and $25 \%$ rebate during off peak hours (between 12 midnight and 6 a.m.). Given this billing structure, our results can be used by the campus administrators for targeting high electrical load sources and scheduling their operation times (e.g., switching off appliances when not required or moving their time of operation to off peak hours), which would lead to significant cost savings.

\section{DATA COLLECTION INFRASTRUCTURE}

We deployed over 200 Schneider Electric EM64XX series meters across 13 buildings in the IIIT-Delhi campus. The campus consists of academic offices, lecture theaters, student residences, faculty housing, library, sport arena, and centralized facilities infrastructure buildings. Each meter collects 10 electrical parameters (e.g., energy, voltage) every 30 seconds. This is in contrast to utilities that generally collect data at much larger granularity (30 minutes or above). Our high resolution data collection allows for more precise energy accounting. For example, we can check if the air conditioning unit is still operating in the lecture halls, after the scheduled classes have finished. 


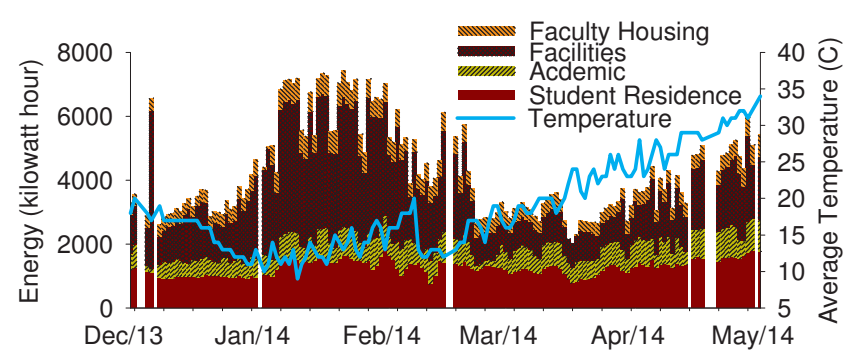

Figure 2: Daily energy consumption

Multiple meters are connected over a common RS485 serial communication bus to Raspberry Pi controllers. These smart controllers pull the data from the interface, and transport the data over the campus LAN. We utilized Simple Measuring and Actuation Profile (sMAP) ${ }^{2}$ to process and visualize the data. We queried the Weather Underground ${ }^{3}$ Web site to collect average daily outside temperature.

Figure 1 shows our smart meter data collection and analysis architecture. Our analysis is based on data collected between Dec 1, 2013 through April 30, 2014. The meter locations are categorized into student residence (e.g., dormitories and food court), academic areas (e.g., offices, lecture halls, library), facilities (e.g., water pumps), and faculty housing (e.g., faculty apartments).

\section{OVERALL ENERGY CONSUMPTION}

Figure 2 shows the campus energy consumption and the average outside daily temperature over the five month period. We observe seasonal variations in energy consumption. For example, there is greater energy consumed during the winter months due to increased use of the centralized heating infrastructure. The correlation between energy consumption and outside temperature was negligible.

Facilities consume much of the energy in the campus. During the winter months, we notice a surge in energy consumption of the hot water heater. We also analyzed the mean energy consumption of the different location categories. We found that while the other locations show a diurnal pattern, the facilities location has almost a flat energy consumption behavior throughout the entire day. About $30 \%$ of the total energy is consumed during peak billing hours.

Figure 3 shows the cumulative percentage of total energy consumed by mutually exclusive individual meter locations. It exemplifies the Pareto principle where few locations are responsible for most of the energy consumed in the campus. For example, the hot water heater consumed over $40 \%$ of the total energy, while faculty housing only consumed $1 \%$ of the total energy. This result could enable the facility manager to focus on optimizing a small subset of loads, which could provide the highest return on energy savings.

\section{ENERGY CONSUMPTION PROFILES}

Our energy consumption profiles are based on manual classification. We aim to devise automatic classification schemes for profiling various campus locations as future work. We identified the hours during the day when energy consumption peaked in the various locations. We omit the

\footnotetext{
${ }^{2}$ http://www.cs.berkeley.edu/ ${ }^{\text {stevedh/smap2/ }}$

${ }^{3}$ http://www . wunderground.com/
}

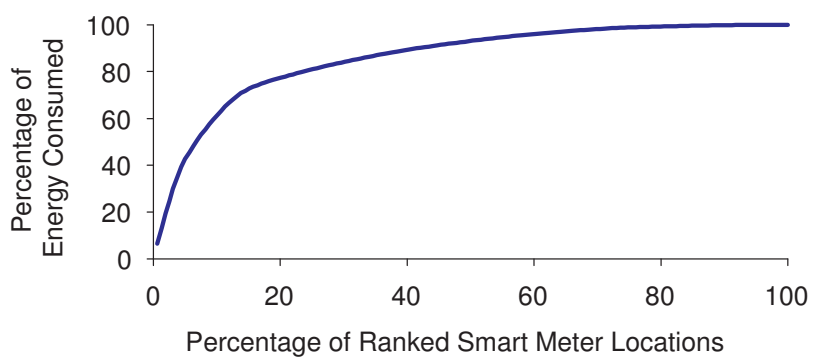

Figure 3: Power-law in energy consumption

\begin{tabular}{|c|c|c|}
\hline LOCATION & LEAST ENERGY CONSUMPTION & MOST ENERGY CONSUMPIION \\
\hline & $\begin{array}{llll}M & T & W & T\end{array}$ & w T \\
\hline $\begin{array}{c}\text { STUDENT } \\
\text { RESIDENCE }\end{array}$ & & \\
\hline ACADEMIC & & \\
\hline FACUITIES & & \\
\hline $\begin{array}{l}\text { FACUITY } \\
\text { HOUSING }\end{array}$ & & \\
\hline
\end{tabular}

Figure 4: Campus energy consumption profiles

graphs due to space limitations. We arrived at three profiles based on when we observe peak energy consumption:

Night peaks: The student residence has peak energy consumption during the night. They consume less energy during the weekend. Most students are in class during the day, and return to their dormitories in the evening. These factors could lead to the night skews observed in our data.

Day peaks: The academic areas have peak energy consumption during regular office hours, and minimum energy consumption during weekends. These results are typical of any enterprise, where most employees are gone by evening.

Random peaks: Faculty housing and the facilities showed random peaks for energy consumption. We noticed peaks during late night and early morning hours for faculty housing. This is counter-intuitive to our understanding, which requires further investigation.

Figure 4 summarizes the profiles of the campus based on energy consumption on day of the week. These results suggest the need for offloading energy consumption to off peak hours, using energy efficient centralized infrastructure appliances, and rescheduling routine operation of such appliances to off peak billing hours.

\section{CONCLUSIONS AND FUTURE WORK}

We presented a first look at energy consumption in an Indian residential community. Utilizing an array of smart meters and the RESTful paradigm, we profiled the campus locations based on their peak energy consumption. We observed skews in energy consumption indicating the presence of power-law behavior, which could be leveraged for energy conservation strategies.

We plan to undertake a comprehensive longitudinal characterization of the campus energy consumption. We aim to further investigate correlation (if any) between outside temperature and change in energy consumption using better statistical methods. We aim to extract salient features of the energy consumption profiles to generate artificial data for simulating future energy demand. We also plan on devising better mechanisms for informing consumers about their energy consumption behavior. 


\section{REFERENCES}

[1] A. Almeida, P. Fonseca, B. Schlomann, and N. Feilberg. Characterization of the household electricity consumption in the eu, potential energy savings and specific policy recommendations. Energy and Buildings, 43(8):1884-1894, 2011.

[2] A. Kavousian and R. Rajagopal. Data-driven benchmarking of building energy efficiency utilizing statistical frontier models. Journal of Computing in Civil Engineering, 28(1):79-88, 2014.

[3] A. Smith, N. Fumo, R. Luck, and P. J. Mago. Robustness of a methodology for estimating hourly energy consumption of buildings using monthly utility bills. Energy and Buildings, 43(4):779 - 786, 2011. 